\section{Questión}

Periodismo / Comunicación ISSN 1669-6581
- Av. $44 \mathrm{~N}^{\circ} 676,1^{\circ}$ piso

CP 1900 - La Plata - Argentina

@ www.perio.unlp.edu.ar/question

Italia y el coronavirus: crónica desde el fin de la cuarentena

Sofía Ramírez Fionda

https://doi.org/10.24215/16696581e392

\title{
Italia y el coronavirus: crónica desde el fin de la cuarentena
}

\section{Italy and coronavirus: chronic since the end of quarantine}

\section{Palabras clave}

Italia - Crónica - Cuarentena - Libertad

\section{Key Words}

Italy - Chronicle - Quarantine - Freedom

Pasaron tres meses desde que el primer caso de coronavirus se detectó en Italia y setenta días desde el primer decreto que instituyó la cuarentena y definió como "zona roja" a las Regiones del Norte del país, aislándolas para evitar la difusión de los casos en todo el territorio nacional. Tres meses que se caracterizaron por un derrumbe de todas las certezas que poseíamos a nivel personal y social, dando paso a una incertidumbre que parece terminar solo ahora, a mediados de mayo, con el anuncio oficial de la flexibilización de las medidas de contención del virus.

Inicialmente, la preocupación no era grave porque las pocas personas que hasta el momento habían resultado positivas habían estado en China y no se encontraban en riesgo de vida. Pero el jueves 20 de febrero, luego de que un hombre de 38 años (el Paciente 1) fuese internado en condiciones muy graves en Codogno, Lombardía, todo cambió: en menos de un día se descubrieron al menos 20 infectados en el Norte de Italia y en pequeños pueblos en los cuales la cadena de contagio y el vínculo con los casos en China no eran (ni lo son todavía) claros. 
Los números del coronavirus en Italia se encuentran entre los peores del mundo, y desde ese lejano 20 de febrero cambiaron mucho. Pasamos de preocuparnos por haber llegado a los 100 contagios, a tener más de 225 mil personas infectadas y 30 mil muertos. Sin embargo, es indispensable comprender que la situación es distinta entre las veinte Regiones que componen la República Italiana, pasando desde el Norte y, particularmente, la Región Lombardía con más de 85 mil contagios, hasta la Región Basilicata en el Sur, con 400.

Por este motivo, el 8 de marzo el gobierno nacional comenzó decretando el aislamiento de la zona roja, en donde las personas podían salir de casa y de la Región solo por motivos de trabajo, salud o necesidad comprobada. Las únicas disposiciones de aplicación nacional fueron el cierre de las escuelas y universidades, la suspensión de viajes de estudio y excursiones, y de todos los eventos deportivos, manifestaciones, eventos públicos y celebraciones religiosas.

Se introdujo una medida que duraría hasta el 18 de mayo: la autocertificación, un módulo que se completaba en caso de solicitud por parte de las fuerzas de seguridad para declarar el motivo de la salida. No se sabe el número exacto de puestos de control que las fuerzas de seguridad organizaron dentro de las ciudades en este período, pero sí que entre el 11 de marzo y el 13 de mayo realizaron más de 14 millones de controles y 440 mil multas. Los comercios sufrieron 5 millones y medio de controles y recibieron 10 mil multas por no respetar las indicaciones de seguridad o la obligación de cerrar.

Solo dos días después del primer decreto, las medidas que se aplicaban en la zona roja fueron extendidas a todo el territorio nacional. Los bares podían abrir desde las 6 de la mañana hasta las 6 de la tarde y los centros comerciales debían permanecer cerrados los fines de semanas, excepto las farmacias, almacenes y supermercados. Los restaurantes podían abrir solo garantizando la distancia de seguridad entre los comensales, lo cual implicó una reducción del número de clientes. Los complejos de esquí, cines, teatros, discotecas, pub, casinos, museos, gimnasios, spa, y demás actividades similares de apertura al público fueron cerradas. La actividad de las iglesias y otros lugares de culto fue condicionada a la adopción de medidas de prevención. Obviamente, desde el inicio de la epidemia se instauró la cuarentena total para las personas positivas al coronavirus y para aquellas sospechadas por haber estado en contacto con un caso confirmado, y cualquier actividad estaba (y sigue estando) sujeta a las medidas de distanciamiento social. 
Desde el 23 de marzo, la cuarentena fue casi total, incluyendo el cierre de restaurantes, bares y comercios, categorizados como "no esenciales" en un nuevo decreto que enumeraba los códigos de las actividades que podían permanecer abiertas, aunque el cierre no afectaba las actividades de delivery, permitidas en cualquier rubro. En paralelo, las regiones y administraciones locales aplicaron y están aplicando medidas específicas de acuerdo a la situación local. Por ejemplo, quienes llegan desde el Norte a una Provincia del Sur, pueden ser obligados a realizar cuarentena preventiva según las disposiciones del gobierno local. Lombardía y Véneto impusieron más restricciones, como el uso obligatorio de la máscara. Calabria se enfrentó al gobierno nacional defendiendo la apertura de los restaurantes con mesas al abierto durante la fase 2, que entró en vigor el 4 de mayo y que trajo consigo el alivio de las medidas.

Dicha fase 2 permitió el movimiento dentro de la Región de residencia para hacer deporte, actividades al abierto y visitas a los familiares. Dos semanas después, el nuevo decreto del 16 de mayo permitió a los habitantes del territorio italiano moverse sin necesidad de justificación, a partir del 4 de junio.

A nivel del debate político, al inicio de la cuarentena, y con el gobierno de coalición conformado por el Movimento 5 Stelle y el Partito Democratico en el poder, los partidos de la oposición (mayormente de centroderecha) reclamaron el cierre total del país. Más adelante en la crisis, discutirían el rol de la Unión Europea y las ayudas económicas que ésta ofrecía y, hacia el final de la cuarentena, reclamarían la flexibilización y apertura de la actividad económica. Poca mención hubo sobre el rol del gobierno y el Estado en la limitación de las libertades de los ciudadanos, un tema que estuvo más presente en el Parlamento que en la televisión italiana.

Durante estos tres meses, no hay sector que no haya cambiado acorde a la nueva realidad y no se haya adaptado a las medidas de prevención impuestas por el gobierno frente al coronavirus. El crecimiento del e-commerce y el delivery de comida es solo un ejemplo. Hablamos no solo de comercios e industrias, obligados a cambiar sus procesos de producción y los mecanismos de venta: incluso a nivel de relaciones sociales, hemos visto afectadas las interacciones más normales como visitar a los familiares y amigos y salir al parque en grupo.

Desde el punto de vista de los medios de comunicación, seguramente es interesante analizar cómo han afrontado la difusión de información referida a la pandemia, tan reclamada por la ciudadanía, y cómo ésta haya influido en sus actividades. Como informa Auditel, sociedad italiana que analiza los números de espectadores y actividades relacionadas, tanto la televisión 
tradicional como las plataformas digitales han registrado incrementos en sus audiencias. Durante la última semana de marzo, la televisión tradicional llegó a un pico de aumento de espectadores del $48 \%$ respecto al mismo periodo en el año anterior, aunque luego la tendencia baja y se mantiene alrededor del $10 \%$.

No obstante la televisión es siempre el principal medio de comunicación, las plataformas de contenidos on demand triplicaron el porcentaje de espectadores. Los programas con mayor número de espectadores e incrementos en visibilidad son los noticieros, particularmente los del horario principal, que registran un crecimiento de hasta el 30\% respecto al mismo periodo en el 2019, y a nivel general los contenidos de noticias e investigación son aquellos más buscados. Podemos presumir que se debe al mayor tiempo que los italianos pasan en sus casas, y quizás también a la necesidad de estar informados en un contexto cambiante y de incertidumbre.

La misma tendencia registra Google Trends, en donde los dos picos de búsqueda de términos relacionados al coronavirus se registran el 23 de febrero (100 puntos, el máximo interés demostrado en un tema) y el 9 de marzo, el día del anuncio del nuevo decreto (79 puntos, interés muy alto).

Durante las últimas semanas de febrero y el mes de marzo, encontramos ediciones de noticieros dedicadas totalmente al coronavirus, que transmiten continuamente el número de contagios, las muertes y quienes fueron curados. Y el sector privado, a través de la publicidad, y los medios de comunicación se unen al mensaje del gobierno, que llama a la ciudadanía a "permanecer unidos para vencer al virus y superar la crisis juntos". Difícilmente se ve una publicidad normal, que no haya sido adaptada a la situación de pandemia.

Según revela Eurispes, los noticieros del servicio público dedican más espacio en su programación a las iniciativas de la sociedad civil para ayudar en la crisis y las dificultades que comporta para las familias, al uso de las nuevas tecnologías para sustituir la distancia física, y a la situación del personal de salud.

También los sitios web de los periódicos registran un incremento notable en las visitas: solo durante las dos primeras semanas de marzo, la Repubblica e il Corriere della Sera, los dos periódicos de mayor tirada nacional, registran hasta un $80 \%$ en el incremento de visitas. Y ganan confianza frente a las redes sociales, según el análisis de Edelman.

El mismo informe demuestra que los italianos se preocupan por la difusión de fake news y cae el uso de las redes sociales como fuente primaria de noticias, incluso en relación a los otros 
países analizados. Más jóvenes son los italianos, más recurren a las redes sociales para informarse, mientras que las personas a partir de los 30 años prefieren los medios tradicionales, sobre todo luego de esta crisis.

Resulta interesante también analizar los indicadores sobre la confianza en las fuentes de información e instituciones presentados por Edelman: científicos, médicos, hospitales e instituciones de salud públicas son las fuentes más confiables para los habitantes de Italia cuando buscan información sobre el virus y la prevención del contagio. Seguramente, las fake news y la elección acertada de las fuentes de información son los argumentos más actuales cuando hablamos de comunicación en la era de Internet y las redes sociales, y en este tema quizás podríamos concluir que frente a la crisis, los italianos han superado la prueba del acceso a la información y la confianza en el criterio científico.

Quizás sea el momento de dar un paso más y reflexionar sobre cuáles son los principios que queremos que nos guíen como sociedad. El criterio científico es válido, pero que sea válido no lo vuelve ni infalible ni de aplicación obligatoria a nivel político. La comunidad científica no posee una sola postura e, incluso durante esta pandemia, han demostrado que las opiniones y recomendaciones pueden cambiar a medida que conocimos mejor el virus. Lo cual está bien, es así que construimos el progreso y nos acercamos cada vez más a la verdad científica: a través del mecanismo de prueba y error. La libertad de acción y de opinión son indispensables para el progreso, y este criterio no cambia en situación de crisis: los principios son válidos solo si los mantenemos, sobre todo, en los momentos de mayor dificultad. 